\title{
Abdominal Distention
}

National Cancer Institute

\section{Source}

National Cancer Institute. Abdominal Distention. NCI Thesaurus. Code C78161.

Swelling of the abdomen resulting from excessive food intake, malnutrition, liver disease,

primary abdominal tumors, and tumors metastatic to the abdominal cavity. 